\title{
Motivation to quit smoking and acceptability of shocking warnings on cigarette packages in Lebanon
}

\section{Nelly Layoun ${ }^{1,2}$ \\ Pascal Salameh ${ }^{2,3}$ \\ Mirna Waked ${ }^{4}$ \\ Z Aoun Bacha ${ }^{5}$ \\ Rony M Zeenny ${ }^{6}$ \\ Eric El Hitti ${ }^{4}$ \\ Isabelle Godin' \\ Michèle Dramaix'}

'Research Center in Epidemiology, Biostatistics and Clinical

Research, School of Public Health, UniversitéLibre de Bruxelles,

Brussels, Belgium; ${ }^{2}$ Doctoral School of

Sciences and Technologies, Lebanese

University, Beirut, Lebanon; ${ }^{3} \mathrm{Clinical}$

and Epidemiological Research

Laboratory, Faculty of Pharmacy,

Lebanese University, Beirut, Lebanon;

${ }^{4}$ Department of Pulmonology, St

George Hospital University Medical

Center; Faculty of Medicine,

Balamand University, Beirut, Lebanon;

${ }^{5}$ Department of Pulmonary and

Critical Care Medicine, Hotel-Dieu

de France, Beirut, Lebanon; ${ }^{6}$ Pharmacy

Practice Department, School of

Pharmacy, Lebanese American

University, Byblos, Lebanon
This article was published in the following Dove Press journal:

Patient Preference and Adherence

24 February 2017

Number of times this article has been viewed

Introduction: Health warnings on tobacco packages have been considered an essential pillar in filling the gap of knowledge and communicating the health risks of tobacco use to consumers. Our primary objective was to report the perception of smokers on the textual health warnings already appearing on tobacco packages in Lebanon versus shocking pictures about the health-related smoking consequences and to evaluate their impact on smoking behaviors and motivation.

Methods: A pilot cross-sectional study was undertaken between 2013 and 2015 in five hospitals in Lebanon. Participants answered a questionnaire inquiring about sociodemographic characteristics, chronic respiratory symptoms, smoking behavior and motivation to quit smoking. Only-text warning versus shocking pictures was shown to the smokers during the interview.

Results: Exactly $66 \%$ of the participants reported that they thought shocking pictorial warnings would hypothetically be more effective tools to reduce/quit tobacco consumption compared to only textual warnings. Also, $31.9 \%$ of the smokers who were motivated to stop smoking reported that they actually had stopped smoking for at least 1 month secondary to the textual warnings effects. A higher motivation to quit cigarette smoking was seen among the following groups of smokers: males (odds ratio $[\mathrm{OR}]=1.8, P=0.02$ ), who had stopped smoking for at least 1 month during the last year due to textual warning ( $\mathrm{OR}=2.79, P<0.001$ ), who considered it very important to report health warning on cigarette packs $(\mathrm{OR}=1.92, P=0.01)$, who had chronic expectoration ( $\mathrm{OR}=1.81, P=0.06)$ and who would change their favorite cigarette pack if they found shocking images on the pack $(\mathrm{OR}=1.95, P=0.004)$.

Conclusion: Low-dependent smokers and highly motivated to quit smokers appeared to be more hypothetically susceptible to shocking pictorial warnings. Motivation to quit was associated with sensitivity to warnings, but not with the presence of all chronic respiratory symptoms.

Keywords: cigarette tobacco smoking, adult smokers, health warnings, cigarette packaging, graphic warning labels, textual warning labels

\section{Introduction}

Tobacco use is a serious and growing health threat worldwide. ${ }^{1}$ It is the leading cause of preventable death, with around 6 million people dying from tobacco use each year. This number is expected to increase by $20 \%$ in $2020 .^{2}$ Smoking is directly associated with causing about $71 \%$ of lung cancer, $42 \%$ of chronic respiratory disease and cardiovascular disease. ${ }^{2,3}$ Several strategies have been considered to reduce the population of smokers. The ban on smoking in public places and increasing the tax on tobacco are currently considered the standards of practice. ${ }^{4}$ However, additional approaches, such as advising and making people aware of the ill effects of smoking, have also been used. ${ }^{5}$ In fact, education about smoking-related illnesses has proven to be an
Correspondence: Nelly Layoun Nada Bakhous Building, Ist floor, Dekwaneh, Mount Lebanon, Lebanon Tel+96I03520362

Email nelly_layoun@hotmail.com 
effective strategy to raise awareness, encouraging individuals to stop smoking. ${ }^{6}$ Health warnings on tobacco packages have been considered an essential pillar in filling this gap of knowledge and communicating the health risks of tobacco use to consumers. ${ }^{6}$ Studies have estimated that smokers are potentially exposed to the warnings over 7,000 times per year. Accordingly, tobacco packages are an essential continuous vehicle to reach out to the target audience, even during the act of smoking. ${ }^{7}$ The value of warnings on tobacco packages extends to nonsmokers as well, since these portable advertisements become available when the product is used and are often left in public view between uses. ${ }^{8}$ The World Health Organization's Framework Convention on Tobacco Control states that "warnings should cover $50 \%$ or more of a package's principal surfaces, and 'may' include pictures". 9 Text-only warnings have traditionally been used as the only form of education on tobacco packs, including large text-based warnings. The latter are associated with better effect on decision making regarding tobacco use, compared to standard text-only warnings. ${ }^{10}$ Text-only warnings are, however, related to the literacy level of smokers, which is reported to be lower than the general public. ${ }^{11}$ Thus, textonly warnings have been rated by smokers as ineffective and unnoticeable. ${ }^{12,13}$ On the contrary, pictorial warnings have been proven to be instrumental in reducing the burden of tobacco use. They are self-reflective on health risks, not limited by literacy level, noticeable ${ }^{12,14,15}$ and are more likely to increase motivation to quit smoking. ${ }^{13,14,16,17}$

In fact, the use of images may be an effective educational strategy, since pictures improve learning, memory and impact post-message attitudes. ${ }^{18-20}$ Pictorial warnings have not only shown reduced tobacco use and consumption, ${ }^{21}$ but also increased smokers' cessation-related thoughts. ${ }^{16,22}$ Pictorial warning labels also constitute an important source of tobacco risks awareness to nonsmokers. ${ }^{23}$ This translates into a wellinformed society that pressures smokers to quit.

As of 2012, 63 countries/jurisdictions have finalized graphic warning labels requirements as covering $50 \%$ or more of the package front and back. Yet, about $40 \%$ of countries still have not implemented any warning label policies or require only small warnings that cover $<30 \%$ of the package. ${ }^{24}$

In Lebanon, text-based warnings are the only adopted mean on the tobacco packages. Moreover, research on the effect of health warning labels from low- and middle-income countries such as Lebanon is still limited. Our study was thus designed to report the perception of textual health warnings already implemented on tobacco packages in Lebanon versus shocking pictures about health-related smoking consequences and to evaluate their impact on smoking behaviors and motivation.

\section{Methods \\ Study design}

From March 2013 to April 2015, a cross-sectional, questionnaire-based study was conducted. Participants were interviewed in the waiting rooms of respiratory outpatients' clinics and/or smoking cessation center in five hospitals in Lebanon distributed in the areas of Beirut $(n=2)$, Mount Lebanon $(n=1)$ and North Lebanon $(n=2)$.

\section{Study participants}

Eligible participants were current exclusive adult cigarette smokers defined as "currently smoking $\geq 1$ cigarette per day" and visiting the clinic for an ordinary check-up or for an acute respiratory disease including pneumonia, bronchitis or a chronic obstructive pulmonary disease. Patients seeking advice for a smoking cessation program were also eligible to participate. Participants were interviewed in Arabic by a health care provider who was trained to use standardized questionnaires. This study design has been previously described in the Italian population. ${ }^{25}$

\section{Ethical consideration}

We obtained ethical approval from the Institutional Review Board of the Lebanese University for this study. A written informed consent was not needed. Participants were informed about the purpose of the study and their voluntary participation. Their verbal consent was obtained before they were interviewed. Data were anonymous and reported in aggregate.

\section{Study tool and variables}

The final version of the standardized questionnaire of the American Thoracic Society was administered in Arabic, the native language of Lebanon; details about the translation process were presented in a study conducted by Waked et al. ${ }^{26}$ Sociodemographic characteristics including age categorized into $<45$ and $\geq 45$ years $^{25}$ and gender were collected. Chronic respiratory problems were assessed using the following definitions: "Chronic respiratory disease diagnosed by a doctor, reported chronic cough, reported chronic phlegm, chronic bronchitis defined as cough and phlegm for $>3$ months per year since 2 years, ${ }^{27}$ cough and phlegm for $>3$ weeks and chronic wheezing".

Smoking behavior details included the number of cigarettes smoked per day and the number of years of smoking cigarette. For the number of cigarettes smoked per day, responses were categorized into $1-9,10-25$ and $>25$ cigarettes per day. ${ }^{25}$ The number of years of smoking for each participant was categorized into $<6,6-15,16-25$ 
and $>25$ years of smoking, with the intention to compare it to the Italian study. ${ }^{25}$

Smoking dependence was assessed using Fagerström scale with $\geq 5$ translated into high dependency. ${ }^{25,28}$ Also, the Mondor scale was used to evaluate the motivation to quit smoking, with a score of $>12$ meaning high motivation to quit. ${ }^{29}$

We also investigated the actual effect of currently used textual warnings on quitting smoking for at least 1 month during the last year and the reduced amount of cigarette smoked daily due to these warnings, by asking two questions:

1) "Have you ever stopped smoking for at least 1 month after reading the textual warnings on the cigarette package?"

2) "Are you or have you been influenced by the health warnings in a way that lead you to (reduce the number of cigarettes you smoked daily)?"

Furthermore, we examined the importance of reporting health warnings on cigarette packages and the influence of these warnings on increasing the curiosity of people to seek the help of a specialist (doctor or pharmacist) to stop smoking, by asking two questions:

1) "Do you consider it important to report the health warnings about tobacco consumption on cigarette packs?" ${ }^{25}$ A lot, enough, poor, no

2) "Have the health warnings increased the curiosity or the desire to be better informed or to be helped to give up smoking?"25 A lot, enough, poor, no.

Finally, after showing the participants a group of shocking pictures about the negative smoking consequences on some body organs (black teeth, dirty lungs and so on), ${ }^{30}$ two items were used to evaluate quantitatively the packaging perception related to its hypothetical impact for smoking cessation or reduction:

1) "If these shocking images were used on tobacco boxes, would they have greater effect than simple warning text currently used?" Yes/no

2) "If your favorite cigarette brand decides to change its look by using these pictorial warnings on tobacco packaging, would you think of buying another cigarette brand?" Yes/no.

\section{Sample calculation}

This pilot trial aimed to recruit 369 smokers. Sample size calculation was done with a $95 \%$ confidence level and a precision of $5 \%$. The mean percentage of Lebanese adults who have ever smoked cigarettes is around $60 \% ;{ }^{31}$ approximately $62 \%$ of the smokers in Italy perceived that warnings with shocking pictures are more effective in reducing/ quitting tobacco consumption than text-only warnings. ${ }^{25}$ Accordingly, we expected that around $60 \%$ of the population of cigarette smokers in Lebanon considered using shocking pictures to have greater effect than the simple warning currently used.

\section{Statistical analysis}

The statistical analysis was carried out using IBM-SPSS version 19 software for Windows Release (IBM Corp. released in 2010 IBM SPSS Statistics for Windows, Version 19.0; IBM Corporation, Armonk, NY, USA). Categorical data were shown as absolute frequencies and percentages. Continuous data were presented as median (interquartile range $[\mathrm{IQR}]=\mathrm{P} 25-\mathrm{P} 75)$. The dichotomous nicotine dependence and motivation to stop smoking variables were compared between groups using the chi-square test.

A multivariable logistic regression analysis was carried out in order to assess the impact of the pictorial warning by using as outcome the two questions concerning the impact of the pictorial warnings. The independent factors included in the models were the following: gender, age groups ( $<45$ years), nicotine dependence (high/low), motivation to stop smoking (high/low) and chronic respiratory symptoms. In addition, another multivariable logistic regression was performed using the motivation to quit as a dependent variable, whereas gender, age groups, dependence scale, textual/ pictorial perception and chronic respiratory symptoms were used as independent variables in the model. Furthermore, we performed a multivariable logistic regression using as outcome a reduction in the number of cigarettes smoked daily with the following independent variables: age, gender, Mondor scale (motivation to quit), scale of dependence, textual/pictorial perception and chronic respiratory symptoms. The odds ratios (ORs) adjusted for the covariates with their 95\% confidence interval were indicated. The Hosmer and Lemeshow test was applied to estimate the goodness of fit for each model. The statistical significance was set at a $P$-value $<0.05$.

\section{Results}

\section{Sample description}

In total, data were collected from 382 cigarette smokers with the response rate of $92 \%$, ranging from $88 \%$ to $96 \%$ in different collection centers. Study participants were mainly males (61\%). Around $49.2 \%$ were $<45$ years. The mean age was 44.52 years (standard deviation $[\mathrm{SD}]=14.1$; Table 1 ).

Concerning the smoking habits of smokers, $52.4 \%$ of our participants indicated that they smoked around 10-25 cigarettes a day, compared to $38 \%$ who reported smoking $>25$ cigarettes 
Table I Description of the sample of cigarette smokers $(\mathrm{N}=382)$

\begin{tabular}{|c|c|}
\hline Variables & n (\%) \\
\hline \multicolumn{2}{|l|}{ Gender } \\
\hline Male & $233(6 I)$ \\
\hline \multicolumn{2}{|l|}{ Age group } \\
\hline$\leq 45$ years & $188(49.2)$ \\
\hline \multicolumn{2}{|c|}{ Number of daily cigarettes } \\
\hline $1-9$ & $37(9.6)$ \\
\hline $10-25$ & $200(52.4)$ \\
\hline$>25$ & $145(38)$ \\
\hline \multicolumn{2}{|l|}{ Years of smoking } \\
\hline$<6$ years & $54(14.2)$ \\
\hline $6-15$ & $106(27.7)$ \\
\hline $16-25$ & $84(22)$ \\
\hline$>25$ & $138(36.1)$ \\
\hline \multicolumn{2}{|c|}{ Fagerstrom score (nicotine dependence) } \\
\hline High & $264(69.1)$ \\
\hline \multicolumn{2}{|l|}{ Mondor scale } \\
\hline High & $179(46.9)$ \\
\hline Yes & $347(90.8)$ \\
\hline \multicolumn{2}{|c|}{$\begin{array}{l}\text { What is the consequence that in the immediate worries you? (multiple } \\
\text { answer question) }\end{array}$} \\
\hline Wrinkles & $138(36.1)$ \\
\hline Skin spots & $79(20.7)$ \\
\hline Breathlessness & $274(71.1)$ \\
\hline Bad breath & $242(63.4)$ \\
\hline Yellow teeth & $224(58.6)$ \\
\hline Yellow fingernails & $104(27.2)$ \\
\hline Hair loss & $91(23.8)$ \\
\hline Bad smelling clothes & $231(60.5)$ \\
\hline \multicolumn{2}{|c|}{ Have you ever stopped smoking due to the warnings? } \\
\hline Yes & $81(2 \mid .2)$ \\
\hline
\end{tabular}

Are you or have you been influenced by the health warnings on cigarette packages (in relation to the number of cigarettes smoked daily)?

Yes

$73(19.1)$

Have you changed your smoking habits due to warnings

(eg, do not smoke after coffee)

Yes

45 ( 11.8$)$

Do you consider it important to report the health warnings about

tobacco consumption on cigarette packs?

A lot $168(44)$

Enough $\quad 44$ (II.5)

Poor $\quad 4 I$ (10.7)

No $\quad$ II 3 (29.6)

Have the messages communicated that smoking ruins your health?

Yes 304 (79.6)

Have the messages communicated to you that smoking causes damage

to those around you, such as your children or family members?

Yes

$322(84.3)$

Have the health warnings increased the curiosity or the desire to be better informed or to be helped to give up smoking?

$\begin{array}{ll}\text { A lot } & 65(17) \\ \text { Enough } & 40(10.5) \\ \text { Poor } & 40(10.5) \\ \text { No } & 221(57.9)\end{array}$

If shocking images were used on cigarette boxes, would they have greater effect than simple warning text currently used?

Yes

$252(66)$

(Continued)
Table I (Continued)

\begin{tabular}{lc}
\hline Variables & $\mathbf{n}(\%)$ \\
\hline If you could choose the types of warning labels on cigarette packs, which \\
one do you feel as more effective in helping to stop smoking? \\
Textual & $18(4.7)$ \\
Graphic & $209(54.7)$ \\
Both & $79(20.7)$ \\
Do not know & $60(15.7)$ \\
If your favorite cigarette brand decided to change look of its cigarette \\
boxes with shocking pictures on smoking health damages, would you \\
think of changing it? \\
\multicolumn{2}{l}{ Yes } \\
\hline
\end{tabular}

per day and $<10 \%$ reported smoking $<10$ cigarettes daily. The median duration of cigarette tobacco use was 20 years (IQR $=10-31$ ), and the median age of smoking first cigarette was 18 years $(\mathrm{IQR}=16-21)$.

In regard to the Fagerström scale, around $69 \%$ of our participants were classified as highly dependent on nicotine. Furthermore, $53.1 \%$ were unfavorably motivated to quit, based on Mondor scale.

Ninety one percent of respondents were aware of the health consequences of smoking. Most of them reported that the short-term concerns from tobacco consumption were breathlessness (71.7\%), bad breath (63.4\%), bad smelling cloths $(60.5 \%)$ and yellow teeth (58.6\%).

\section{Warning labels recognized effects}

Currently used textual warnings on smoking habits were reported to have actually triggered a smoking cessation trial for at least 1 month and a reduction in the number of cigarettes smoked a day in $21 \%$ and $19.1 \%$ of cigarette smokers, respectively. Around $12 \%$ of the participants reported that they stopped smoking when they woke up in the morning or after drinking coffee due to the textual warnings. Furthermore, $66 \%$ of the participants reported that they thought shocking pictorial warnings would hypothetically be more effective tools to reduce/quit tobacco consumption compared to only textual warnings and the graphics were the most preferred (54.7\%) compared to only-text warning (4.7\%) and the association of text/pictures (20.7\%). Also, the findings indicate that $48.4 \%$ of the participants would change their cigarette brand if the smoking health damage warnings of that brand would change to shocking pictures (Table 1).

\section{Warning labels, gender and age groups}

Women seemed to be more affected by the physical effects of smoking, particularly the appearance of wrinkles and skin 
spots $(47 \%, P=0.002$ and $28.5 \%, P=0.01$, respectively). More women reported that currently used health warnings increased their desire to be well informed and/or and to give up on smoking, compared to men (19.4\% versus $16.7 \%)$. Women were more inclined to cease from buying their favorite cigarette pack in case there was pictorial smoking awareness on their cigarette package ( $59 \%$ of females versus $45 \%$ males, $P=0.03$; Table 2 ).

On the other hand, males reported being more worried about their physical fitness getting affected as a consequence of having smoking-related shortness of breath $(80.6 \%$ versus $66 \%, P=0.002$ ). They highlighted the importance of reporting health warning about tobacco consumption on cigarette packs (50\% versus $39.6 \%, P=0.02)$.
Table 2 also shows the comparison by age groups. No significant differences between young and old smokers were found with respect to health warnings, except for yellow teeth (56.2\% versus $66.3 \%$ for $\leq 45$ years, $P=0.04$ ).

\section{Warning labels, dependence and motivation to quit smoking}

The analysis showed that smokers who were motivated to stop smoking reported to actually having stopped smoking for at least 1 month secondary to the textual warnings effects, compared to the group of smokers who were not motivated to stop smoking ( $31.9 \%$ versus $14.3 \%, P<0.001$; Table 3 ). Furthermore, the motivated group reduced the daily consumption of cigarettes $(25.8 \%$ versus $15.3 \%, P=0.01)$ and/

Table 2 Description and comparison of cigarette smokers by gender and age group

\begin{tabular}{|c|c|c|c|c|c|c|}
\hline Variables & Male, n (\%) & Female, n (\%) & $P$-value & $\leq 45$ years, $n(\%)$ & $>45$ years, $n(\%)$ & P-value \\
\hline \multicolumn{7}{|c|}{ Are you aware of the damage caused by smoking? } \\
\hline Yes & $207(93.2)$ & 140 (97.2) & 0.09 & $174(96.1)$ & $173(93.5)$ & 0.26 \\
\hline \multicolumn{7}{|c|}{ What is the consequence that in the immediate worries you? (multiple answer question) } \\
\hline Wrinkles & $70(31.5)$ & $68(47.2)$ & 0.002 & $74(40.9)$ & $64(34.6)$ & 0.21 \\
\hline Skin spots & $38(17.1)$ & $4 I(28.5)$ & 0.01 & $4 \mathrm{I}(22.7)$ & $38(20.5)$ & 0.62 \\
\hline Breathlessness & 179 (80.6) & $95(66.0)$ & 0.002 & $136(75.1)$ & 138 (74.6) & 0.9 \\
\hline Bad breath & 155 (69.8) & $87(60.4)$ & 0.06 & $127(70.2)$ & II5 (62.2) & 0.11 \\
\hline Yellow teeth & $139(62.6)$ & $85(59)$ & 0.49 & $120(66.3)$ & $104(56.2)$ & 0.04 \\
\hline Yellow fingernails & $58(26.1)$ & $46(31.9)$ & 0.23 & $50(27.6)$ & $54(29.2)$ & 0.74 \\
\hline Hair loss & $45(20.3)$ & $46(31.9)$ & 0.01 & $45(24.9)$ & $46(24.9)$ & 0.99 \\
\hline Bad smelling clothes & $150(67.6)$ & $81(56.3)$ & 0.03 & $119(65.7)$ & $112(60.5)$ & 0.3 \\
\hline \multicolumn{7}{|c|}{ Ever stopped smoking due to the warnings? } \\
\hline Yes & $50(22.5)$ & $31(21.5)$ & 0.82 & $40(22.1)$ & $4 I(222)$ & 0.98 \\
\hline \multicolumn{7}{|c|}{ Are you or have you been influenced by the health warnings on cigarette packages (the number of cigarettes smoked daily)? } \\
\hline Yes & $50(22.5)$ & $23(16)$ & 0.12 & $29(16)$ & $44(23.8)$ & 0.06 \\
\hline \multicolumn{7}{|c|}{ Have you changed your smoking habits due to the warnings (eg, do not smoke after coffee)? } \\
\hline Yes & $29(13.1)$ & $16(11.1)$ & 0.58 & $21(11.6)$ & $24(0.69)$ & 0.69 \\
\hline \multicolumn{7}{|c|}{ Do you consider it important to report the health warnings about tobacco consumption on cigarette packs? } \\
\hline A lot & III (50) & $57(39.6)$ & 0.02 & $84(46.4)$ & $84(45.4)$ & 0.69 \\
\hline Enough & $18(8.1)$ & $26(18.1)$ & & $19(10.5)$ & $25(13.5)$ & \\
\hline Poor & $25(11.3)$ & $16(11.1)$ & & $23(12.7)$ & $18(9.7)$ & \\
\hline No & $68(30.6)$ & $45(31.3)$ & & $55(30.4)$ & $58(31.4)$ & \\
\hline \multicolumn{7}{|c|}{ Have the messages communicated that smoking ruins your health? } \\
\hline Yes & $185(83.3)$ & $119(82.6)$ & 0.86 & $145(80.1)$ & $159(85.9)$ & 0.14 \\
\hline \multicolumn{7}{|c|}{ Have the messages communicated to you that smoking causes damage to those around you, such as your children or family members? } \\
\hline Yes & $196(88.3)$ & $126(87.5)$ & 0.82 & $160(88.4)$ & $162(87.6)$ & 0.8 \\
\hline \multicolumn{7}{|c|}{ Have the health warnings increased the curiosity or the desire to be better informed or to be helped to give up smoking? } \\
\hline A lot & $37(16.7)$ & $28(19.4)$ & 0.009 & $28(15.5)$ & $37(20)$ & 0.72 \\
\hline Enough & $15(6.8)$ & $25(17.4)$ & & $20(\mathrm{II})$ & $20(10.8)$ & \\
\hline Poor & $26(I I .7)$ & $14(9.7)$ & & $2 I(I I .6)$ & $19(10.3)$ & \\
\hline No & 144 (64.9) & $77(53.5)$ & & $112(61.9)$ & $109(58.9)$ & \\
\hline \multicolumn{7}{|c|}{ If shocking images were used on cigarette boxes, would they have greater effect than simple warning text currently used? } \\
\hline Yes & $149(67.1)$ & $103(71.5)$ & 0.37 & $125(69.1)$ & $127(68.6)$ & 0.93 \\
\hline \multicolumn{7}{|c|}{ If you could choose the types of warning labels on cigarette packs, which one do you feel as more effective in helping to stop smoking? } \\
\hline Textual & II (5) & $7(4.9)$ & 0.96 & $10(5.5)$ & $8(4.3)$ & 0.14 \\
\hline Graphic & $128(57.7)$ & $81(56.3)$ & & $113(62.4)$ & $96(519)$ & \\
\hline Both & $46(20.7)$ & $33(22.9)$ & & 32 (I7.7) & $47(25.4)$ & \\
\hline \multicolumn{7}{|c|}{ If your favorite cigarette brand decided to change look of its boxes with shocking pictures on smoking health damages, would you think of changing it? } \\
\hline Yes & $100(45)$ & $85(59)$ & 0.03 & $91(50.3)$ & $94(50.8)$ & 0.36 \\
\hline
\end{tabular}


Table 3 Description and comparison of cigarette smokers by motivation score and dependence score

\begin{tabular}{|c|c|c|c|c|c|c|}
\hline Variables & $\begin{array}{l}\text { Low motivation, } \\
\text { n (\%) }\end{array}$ & $\begin{array}{l}\text { High motivation, } \\
\text { n (\%) }\end{array}$ & $P$-value & $\begin{array}{l}\text { Low dependence, } \\
\text { n (\%) }\end{array}$ & $\begin{array}{l}\text { High dependence, } \\
\text { n (\%) }\end{array}$ & $P$-value \\
\hline \multicolumn{7}{|c|}{ Aware of the damage caused by smoking? } \\
\hline Yes & $190(93.6)$ & $157(96.3)$ & 0.24 & 107 (93.9) & $240(95.2)$ & 0.58 \\
\hline \multicolumn{7}{|c|}{ What is the consequence that in the immediate worries you? (multiple answer question) } \\
\hline Wrinkles & $65(32)$ & $73(44.8)$ & 0.01 & $5 I(44.7)$ & $87(34.5)$ & 0.06 \\
\hline Skin spots & $46(22.7)$ & $33(20.2)$ & 0.57 & $27(23.7)$ & $52(20.6)$ & 0.51 \\
\hline Breathlessness & | 45 (7I.4) & $129(79.1)$ & 0.09 & $80(70.2)$ & $194(77)$ & 0.16 \\
\hline Bad breath & $132(65)$ & $110(67.5)$ & 0.62 & $74(64.9)$ & $168(66.7)$ & 0.74 \\
\hline Yellow teeth & $117(57.6)$ & $107(65.6)$ & 0.12 & $70(61.4)$ & I54 (6I.I) & 0.96 \\
\hline Yellow fingernails & $52(25.6)$ & $52(31.9)$ & 0.18 & $40(35.1)$ & $64(25.4)$ & 0.06 \\
\hline Hair loss & $47(23.2)$ & $44(27)$ & 0.39 & $32(28.1)$ & $59(23.4)$ & 0.34 \\
\hline Bad smelling clothes & $120(59.1)$ & III (68.I) & 0.07 & $66(57.9)$ & $165(65.5)$ & 0.16 \\
\hline \multicolumn{7}{|c|}{ Ever stopped smoking due to the warnings? } \\
\hline Yes & $29(14.3)$ & $52(31.9)$ & $<0.001$ & $28(24.6)$ & $53(2 I)$ & 0.45 \\
\hline \multicolumn{7}{|c|}{ Are you or have you been influenced by the health warnings on cigarette packs (number of cigarettes smoked daily)? } \\
\hline Yes & $3 \mid(\mid 5.3)$ & $42(25.8)$ & 0.01 & $30(26.3)$ & $43(17.1)$ & 0.04 \\
\hline \multicolumn{7}{|c|}{ Have you changed your smoking habits due to warnings (eg, do not smoke after coffee)? } \\
\hline Yes & $14(6.9)$ & $31(19)$ & $<0.001$ & $20(17.5)$ & $25(9.9)$ & 0.04 \\
\hline \multicolumn{7}{|c|}{ Do you consider it important to report the health warnings about tobacco consumption on cigarette packs? } \\
\hline A lot & $71(35)$ & $97(59.5)$ & $<0.001$ & $58(50.9)$ & $110(43.7)$ & 0.008 \\
\hline Enough & $28(13.8)$ & $16(9.8)$ & & $21(18.4)$ & $23(9.1)$ & \\
\hline Poor & $26(12.8)$ & $15(9.2)$ & & $8(7)$ & $33(13.1)$ & \\
\hline No & $78(38.4)$ & $35(21.5)$ & & $27(23.7)$ & $86(34.1)$ & \\
\hline \multicolumn{7}{|c|}{ Have the messages communicated that smoking ruins your health? } \\
\hline Yes & $162(79.8)$ & $142(87.1)$ & 0.06 & $94(82.5)$ & $210(83.3)$ & 0.84 \\
\hline \multicolumn{7}{|c|}{ Have the messages communicated to you that smoking causes damage to those around you, such as your children or family members? } \\
\hline Yes & $175(86.2)$ & $147(90.2)$ & 0.24 & $101(88.6)$ & $221(87.7)$ & 0.8 \\
\hline \multicolumn{7}{|c|}{ Have the health warnings increased the curiosity or the desire to be better informed or to be helped to give up smoking? } \\
\hline A lot & $31(15.3)$ & $34(20.9)$ & 0.49 & I8 (I5.8) & $47(18.7)$ & 0.03 \\
\hline Enough & $24(11.8)$ & $16(9.8)$ & & $20(17.5)$ & $20(7.9)$ & \\
\hline Poor & $21(10.3)$ & $19(11.7)$ & & $15(13.2)$ & $25(9.9)$ & \\
\hline No & $127(62.6)$ & $94(60.4)$ & & $61(53.5)$ & $160(63.5)$ & \\
\hline \multicolumn{7}{|c|}{ If shocking images were used on cigarette boxes, would they have greater effect than simple warning text currently used? } \\
\hline Yes & $127(62.6)$ & $125(76.7)$ & 0.004 & $89(78.1)$ & $163(64.7)$ & 0.01 \\
\hline \multicolumn{7}{|c|}{ If you could choose the types of warning labels on cigarette packs, which one do you feel as more effective in helping to stop smoking? } \\
\hline Textual & $9(4.4)$ & $9(5.5)$ & 0.05 & $6(5.3)$ & $12(4.8)$ & 0.34 \\
\hline Graphic & III (54.7) & $98(60.1)$ & & $71(62.3)$ & I $38(54.8)$ & \\
\hline Both & $40(19.7)$ & $39(23.9)$ & & $24(2 I . I)$ & $55(21.8)$ & \\
\hline \multicolumn{7}{|c|}{$\begin{array}{l}\text { If your favorite cigarette brand decided to change look of its cigarette boxes with shocking pictures on smoking health damages, would you think } \\
\text { of changing it? }\end{array}$} \\
\hline Yes & $88(43.3)$ & $97(59.5)$ & 0.008 & $65(57)$ & $120(47.6)$ & 0.17 \\
\hline
\end{tabular}

or refrained from smoking after a cup of coffee (19\% versus $6.9 \%, P<0.001)$ after seeing the textual warning. The same group considered the current textual health warnings reported on cigarette packages essential to increase the awareness and motivation to reduce/quit tobacco consumption $(59.5 \%$ versus $35 \%$ ).

Participants with high motivation reported more frequently that pictorial warnings would hypothetically be more effective communication tools to reduce/quit tobacco consumption, compared to currently used only-textual warnings $(76.7 \%$ versus $62.6 \%, P=0.004)$. They would be most effective to fight smoking (60.1\% versus $54.7 \%$ ). Furthermore, highly motivated participants would not buy their favorite cigarette brand if there were printed images on the health effects of smoking (59.5\% versus $43.3 \%, P=0.008$; Table 3 ).

On the contrary, the group of smokers with high nicotine dependence reported that they were less influenced by the current health warnings on cigarette packs (daily number of cigarettes smoked: $17.1 \%$ versus $26.3 \%, P=0.04$ ) and that they were more resistant to changing their smoking habits $(9.9 \%$ versus $17.5 \%, P=0.04)$. Moreover, the highly dependent smokers reported that health warnings did not affect their desire to be well informed and to give up on smoking, compared to low-dependent smokers $(63.5 \%$ 
versus $53.5 \%, P=0.03$ ). The same group reported being less impressed by the hypothetical impact of shocking images (64.7\% versus $78.1 \%, P=0.01$ ) and did not consider the health labels as crucial elements to increase the awareness and/or the motivation to quit $(43.7 \%$ versus $50.9 \%$, $P=0.008$; Table 3).

\section{Effects of chronic respiratory symptoms}

The presence of chronic health symptoms was not statistically associated either with the motivation to quit smoking or with the hypothetical effect of shocking images/textual warnings on tobacco packs on quitting/reducing cigarettes and the switching of the favorite brand (Table 4).

\section{Multivariable analysis}

Multivariable logistic "regression 1" analysis showed that shocking pictorial warnings were significantly two times more hypothetically effective in reducing the smoking behavior in motivated and lower dependent smokers ( $\mathrm{OR}=2, P=0.004$ and $\mathrm{OR}=1.88, P=0.018$, respectively). On the other hand, another multivariable analysis "regression 2 " revealed significantly more females and more motivated smokers changing the favorite cigarette brand due to the inclusion of shocking images $(\mathrm{OR}=1.92, P=0.004$ and $\mathrm{OR}=2.08, P=0.001$, respectively; Table 5).

Indeed, Table 5 shows the multivariable logistic analysis of the motivation to quit "regression 3". It indicates a significantly higher motivation to quit cigarette smoking among male smokers $(\mathrm{OR}=1.80$ for males versus females, $P=0.02$ ), who had stopped smoking for at least 1 month during the last year due to the textual warning $(\mathrm{OR}=2.79$, $P<0.001$ ), who considered it very important to report health warning on cigarette packs $(\mathrm{OR}=1.92, P=0.01)$, who had chronic expectoration $(\mathrm{OR}=1.81, P=0.06)$ and who would change their favorite cigarette pack if there were shocking images on the pack $(\mathrm{OR}=1.95, P=0.004)$.

Table 6 shows the multivariable analysis of the reduction in the number of cigarettes smoked daily due to the warnings; we found a higher reduction among males $(\mathrm{OR}=1.86$, $P=0.04)$, smokers aged $\geq 45$ years $(\mathrm{OR}=2.2, P=0.007)$, smokers who were motivated to quit $(\mathrm{OR}=2.13, P=0.007)$ and low-dependent smokers $(\mathrm{OR}=1.88, P=0.03)$. Indeed, a higher reduction was seen among smokers who had cough and expectoration for $>3$ months/year since 2 years $(\mathrm{OR}=2.7$, $P=0.002)$, whereas it was inversely associated with chronic wheezing $(\mathrm{OR}=0.43, P=0.06)$.

\section{Discussion}

This study assessed the Lebanese adult cigarette users' response to the textual health warnings, covering only $40 \%$ of the two primary surfaces of cigarette containers, and their perception of the future implementation of graphic warnings on packages. Similar to a study done on Canadian students,${ }^{32}$ the majority of our study participants

Table 4 Bivariate analysis: Mondor scale, boxes shocking (pictorial/textual), change brand

\begin{tabular}{|c|c|c|c|c|}
\hline Mondor scale (motivation to quit) & No (N=203), n (\%) & Yes $(\mathbf{N}=179), \mathbf{n}(\%)$ & $P$-value & OR $(95 \% \mathrm{CI})$ \\
\hline Disease declared by doctors (yes) & $31(15.3)$ & $26(14.5)$ & 0.84 & $0.94(0.54-1.66)$ \\
\hline Chronic cough (yes) & $47(23.2)$ & $35(19.6)$ & 0.39 & $0.81(0.49-1.32)$ \\
\hline Chronic expectoration (yes) & $49(24.1)$ & $48(26.8)$ & 0.55 & $1.15(0.73-1.83)$ \\
\hline Cough and expectoration $>3$ months (yes) & $51(25.1)$ & $38(21.2)$ & 0.37 & $0.8(0.50-1.30)$ \\
\hline Cough and expectoration $>3$ weeks (yes) & $36(17.7)$ & $31(17.3)$ & 0.91 & $0.97(0.57-1.65)$ \\
\hline Wheezing (yes) & $26(12.8)$ & $23(12.8)$ & 0.99 & $\mathrm{I}(0.55-\mathrm{I} .83)$ \\
\hline $\begin{array}{l}\text { Would shocking images have greater effect } \\
\text { than simple warning text currently used? }\end{array}$ & No $(n=1 \mid 4)$ & Yes $(n=252)$ & & \\
\hline Disease declared by doctors (yes) & $16(14)$ & $40(15.9)$ & 0.65 & $1.16(0.62-2.16)$ \\
\hline Chronic cough (yes) & $24(21.1)$ & $53(2 I)$ & 0.99 & $\mathrm{I}(0.58-1.72)$ \\
\hline Chronic expectoration (yes) & $26(22.8)$ & $66(26.2)$ & 0.49 & $1.2(0.7 \mid-2.02)$ \\
\hline Cough and expectoration $>3$ months (yes) & $24(21.1)$ & $62(24.6)$ & 0.46 & $1.22(0.72-2.09)$ \\
\hline Cough and expectoration $>3$ weeks (yes) & $17(14.9)$ & $48(19)$ & 0.34 & $1.34(0.73-2.45)$ \\
\hline Wheezing (yes) & $14(12.3)$ & $34(13.5)$ & 0.75 & I.II (0.57-2.17) \\
\hline $\begin{array}{l}\text { If they decided to put shocking pictures on } \\
\text { packs, would you think of changing it? }\end{array}$ & No $(n=181)$ & Yes $(n=185)$ & & \\
\hline Disease declared by doctors (yes) & $26(14.4)$ & $30(16.2)$ & 0.62 & $1.15(0.65-2.04)$ \\
\hline Chronic cough (yes) & $40(22.1)$ & $37(20)$ & 0.62 & $0.88(0.53-1.46)$ \\
\hline Chronic expectoration (yes) & $46(25.4)$ & $46(24.9)$ & 0.9 & $0.97(0.6 I-1.56)$ \\
\hline Cough and expectoration $>3$ months (yes) & $39(21.5)$ & $47(25.4)$ & 0.38 & $1.24(0.76-2.01)$ \\
\hline Cough and expectoration $>3$ weeks (yes) & $29(16)$ & $36(19.5)$ & 0.39 & $1.27(0.74-2.17)$ \\
\hline Wheezing (yes) & $22(12.2)$ & $26(14.1)$ & 0.59 & $1.18(0.64-2.17)$ \\
\hline
\end{tabular}

Abbreviations: $\mathrm{Cl}$, confidence interval; $\mathrm{OD}$, odds ratio. 
Table 5 Multivariate logistic models

\begin{tabular}{|c|c|c|}
\hline Factors & OR (95\% Cl) & P-value \\
\hline \multicolumn{3}{|c|}{ Regression I: Shocking images used on cigarette boxes have greater effect than simple warning text as a dependent variable } \\
\hline$\geq 45$ versus $<45^{*}$ years & $1.02(0.64-1.63)$ & 0.92 \\
\hline Female versus male* & $1.27(0.78-2.05)$ & 0.34 \\
\hline High versus low* motivation to quit & $2.01(0.25-3.21)$ & 0.004 \\
\hline Low versus high* nicotine dependence & $1.88(1.11-3.16)$ & 0.018 \\
\hline \multicolumn{3}{|c|}{ Regression 2: Change the favorite cigarette brand if they implement shocking images on boxes as a dependent variable } \\
\hline$\geq 45$ versus $<45^{*}$ years & $0.97(0.63-1.5)$ & 0.89 \\
\hline Female versus male* & $1.92(1.22-3.01)$ & 0.004 \\
\hline High versus low* motivation to quit & $2.08(1.35-3.2)$ & 0.001 \\
\hline Low versus high* nicotine dependence & $1.35(0.86-2.14)$ & 0.19 \\
\hline \multicolumn{3}{|l|}{ Regression 3: Predictors of the motivation to quit cigarette smoking } \\
\hline Male versus female* & $1.8(1.12-2.91)$ & 0.02 \\
\hline$\geq 45$ versus $45^{*}$ years & $0.67(0.42-1.05)$ & 0.08 \\
\hline Chronic expectoration (yes/no*) & $1.81(0.97-3.39)$ & 0.06 \\
\hline Cough and expectoration $>3$ months/year since 2 years (yes/no*) & $0.52(0.27-0.99)$ & 0.05 \\
\hline Stop smoking due to warnings (at least I month) (yes/no*) & $2.78(1.63-4.75)$ & $<0.001$ \\
\hline If they decided to put shocking pictures on packs, would you think of changing it? (yes/no*) & $1.94(1.23-3.08)$ & 0.005 \\
\hline Consider it important to report health warnings about tobacco consumption on packs? (yes/no*) & $1.91(1.16-3.16)$ & 0.01 \\
\hline Low versus high* nicotine dependence & $1.09(0.67-1.77)$ & 0.72 \\
\hline
\end{tabular}

Note: *Reference group.

Abbreviations: $\mathrm{Cl}$, confidence interval; $\mathrm{OD}$, odds ratio.

acknowledged that pictorial warnings would hypothetically be more effective than only-text warnings in reducing/the attempt to quit smoking. This is also supported by various other reports. ${ }^{25,33-39}$

Findings from both experimental and population-based studies demonstrated that pictorial health warnings are more likely to be noticed and read by smokers than text-only warnings and that they are associated with greater motivation to quit smoking. ${ }^{18}$ Furthermore, most of the proposed labels by Cameron et al enhanced fear-related reactions about the health consequences of smoking and also enhanced the motivation to quit, relative to text-only labels. ${ }^{40}$ Experimental research on cigarette warnings has also found that picturebased warnings are more likely to be rated as more effective than text-only warnings on a range of outcomes, including being a deterrent for new smokers and a means to increase cessation among current smokers. ${ }^{41,42}$ In addition, the inclusion of pictures on one side of the cigarette pack increased smoking avoidance in France and the UK. ${ }^{43}$ Prominent health warnings that cover a significant proportion of the package, particularly pictorial warnings, have the potential to undermine a brand's appeal and the impact of package displays at retail outlets. ${ }^{44-49}$

Interestingly, our study also revealed that females were significantly more affected by the impact of smoking on the appearance of wrinkles, hair loss and skin spots. In fact, Mannocci et al highlighted this concept and showed that women were significantly more susceptible to the immediate consequences of smoking (appearance of wrinkles) and more prone to switch to light cigarettes. ${ }^{38}$ It is further proven that women judged the pictorial warnings as more aversive than men; consequently, the more aversive a

Table 6 Multivariate logistic models to evaluate the reduction in the number of cigarettes due to the textual warning

\begin{tabular}{|c|c|c|}
\hline \multirow[t]{3}{*}{ Independent variables } & \multicolumn{2}{|l|}{ Outcomes } \\
\hline & \multicolumn{2}{|c|}{$\begin{array}{l}\text { Reduction in the number of cigarettes due } \\
\text { to the textual warnings }\end{array}$} \\
\hline & OR $(95 \% \mathrm{Cl})$ & $P$-value \\
\hline Male versus female* & $1.86(1.03-3.38)$ & 0.04 \\
\hline$\geq 45$ versus $<45^{*}$ years & $2.2(1.24-3.90)$ & 0.007 \\
\hline High versus low* motivation to quit & $2.13(1.23-3.70)$ & 0.007 \\
\hline Cough and expectoration $>3$ months/year (yes/no*) since 2 years & $2.7(1.46-4.99)$ & 0.002 \\
\hline Chronic wheezing (yes/no*) & $0.43(0.17-1.06)$ & 0.06 \\
\hline Low versus high* nicotine dependence & $1.88(1.07-3.29)$ & 0.03 \\
\hline
\end{tabular}

Note: *Reference group.

Abbreviations: $\mathrm{Cl}$, confidence interval; $\mathrm{OD}$, odds ratio. 
warning, the more it is perceived as effective against smoking. ${ }^{50,51}$ Furthermore, Mannocci et al showed that females were more affected by the shocking images in reducing tobacco consumption. ${ }^{25}$ More than $50 \%$ of female smokers reported they would change their favorite cigarette brand if the manufacturing company implements pictorial shocking warnings on the cigarette pack, which is in line with another study. ${ }^{25}$

Concern over health risks is the most common motivation for quitting smoking. ${ }^{52,53}$ Health warnings on tobacco packages are among the most prominent interventions to convey the health risks of smoking. Previous studies have demonstrated that smokers with greater knowledge of the health risks of smoking were more likely to intend to quit and were more successful in their quit attempts. ${ }^{54,55}$ In our study, the health warning labels increased the curiosity of around $20 \%$ of females to be better informed or be helped to stop smoking. Similarly, in a study by Koval et al, female current smokers were more likely to think about quitting smoking. ${ }^{56}$ Furthermore, males were significantly more affected by the health warnings related to physical fitness ability, particularly shortness of breath. According to several studies, $22,25,34,38,57,58$ younger people are more sensitive to warnings; on the other hand, Hammond et al found that older smokers rated warnings as more effective. ${ }^{34}$

However, in our sample, there was no statistically significant difference between younger and older smokers in rating the efficacy of different types of warnings; meanwhile, both considered shocking pictorial warnings have greater effect than simple warning text currently used (68.6\% versus $69.1 \%$ for $>45$ years and $\leq 45$ years, respectively). Our results were similar to those reported by Hammond et al where the interaction between age group and graphic internal versus graphic external was not significant. ${ }^{34}$

A greater hypothetical effect of shocking images on cigarette boxes was significantly associated with lower nicotine dependency levels of smokers among the present study population. Furthermore, the lower dependence smokers considered it significantly important to report health warnings on packages. A statistically significant higher hypothetical effect of the shocking pictures was found among low-dependent smokers in our study, consistent with another research. ${ }^{25}$ Moreover, a statistically significant better impact on more motivated smokers was found, which was similar to the results of Mallikarjun et al where a higher sensitivity to pictorial warning labels was significantly associated with lower dependency scale. ${ }^{59}$ Loeber et al suggested the use of pictorial health warnings as an effective public health strategy to reduce the inclination toward cigarette packages of light smokers ( $<20$ cigarettes/day) ${ }^{60}$ Moreover, levels of perceived effectiveness of health warnings have been found to be higher among low-dependent smokers and less-committed smokers. ${ }^{61}$ Finally, a higher decrease in the number of cigarettes smoked daily and a reduction of their smoking habits due to the textual warnings were found among lower dependence smokers. Consequently, this study highlighted that the exposure of smokers with low nicotine dependence to tobacco warning labels helps educating them about the health risks of tobacco smoking and subsequently guides them to quit smoking. Sequentially, in our opinion, later this could create a dilemma: "Is it the high nicotine dependence that induces insensitivity to pictorial and written warnings or the insensitivity to such warnings which is a phenotype that induces high addiction?" Subsequently, this could be explained by the reverse causality concept. Concerning the motivation to quit variable, our study showed that the group highly motivated to quit cigarette smoking considered that the warnings with shocking pictures would hypothetically have significantly greater effect than the textual warnings used alone on the reduction/quitting behavior. These findings are consistent with a report showing that vivid pictures that convey high threat are some ways in which the labels could be designed to enhance perceived susceptibility. ${ }^{62}$

Around $60 \%$ of the highly motivated participants considered health warnings on cigarette packages to be very important, compared to $35 \%$ of the unmotivated individuals. Indeed, around 32\% stopped cigarette smoking for at least 1 month due to the currently used textual warning, compared to $14 \%$ of unmotivated smokers. This has been demonstrated in other studies where participants who had made a quit attempt were most motivated by the labels about their own risks of smoking. ${ }^{62}$ In Italy, reporting negative labels concerning the risk on the health was found to highly influence the subgroup of cigarette smokers who were highly motivated to quit. ${ }^{25}$

On the other hand, research has shown that motivation to quit is associated with making quit attempts. ${ }^{63,64}$ Usually, one approach to increase motivation in order to change behaviors such as quitting smoking is theorized by the extended parallel process model, which assumes that individuals are motivated to act through fear if they perceive a high level of risk from their engagement in an unhealthy behavior, specifically that they are susceptible to negative consequences such as chronic health symptoms. ${ }^{65}$ However, in our study, having chronic health symptoms was sometimes inversely correlated to the motivation to quit $(\mathrm{OR}<1)$; only chronic expectoration 
showed a positive association with motivation to quit. This might be due to the smokers being unaware of the danger of tobacco use on health. Therefore, tobacco control messaging that aims to increase smokers' motivation to quit should contain both threat and efficacy messages to increase the risk perceptions and efficacy beliefs. Labels have largely relied on fear appeals to increase smokers' risk perceptions using depictions of the negative effects of smoking. ${ }^{18}$ The threat portrayed in a message - characterized by susceptibility to health conditions - intrinsically motivates action through fear by increasing individuals' perceptions of their risk ${ }^{65}$ and consequently promotes cessation-related attitudes and behaviors. ${ }^{18,34}$ Alarmingly, threat messages might not appear to be sufficient to motivate changing behavior in our country, in which smoking risk might be considered lower than other risks, such as the political situation and the actual situation of Lebanon in the Middle Eastern countries. Such messages must be accompanied by professional and social support, motivation sessions and information about the centers where they can seek help.

Concerning the influence of chronic bronchitis (cough and phlegm for $>3$ months/years since 2 years) on the motivation to quit with an $\mathrm{OR}=0.52$, this result might be explained by the fact that people who have more episodes of cough and phlegm (chronic bronchitis) are the ones who consider that smoking does not affect the respiratory system; therefore, they continue to smoke and are not motivated to quit cigarette smoking.

Moreover, we noticed that the motivation to quit as well as a reduction in the number of cigarettes smoked daily were frequently observed among male smokers, which is similar to the results of Osler et $\mathrm{al}^{66}$ and Hymowitz et $\mathrm{al}^{67}$ indicating that male gender was a predictor of smoking cessation. On the contrary, McAllister et al showed that females considered seriously cutting down the number of cigarettes they smoked compared to males, but males were more likely to have intentionally quit smoking for at least 1 day within the past year. ${ }^{68}$ Indeed, cutting down the number of cigarettes smoked daily may reduce the harm caused by smoking and may also be a step toward stopping smoking completely. ${ }^{69}$

\section{Limitations}

There are some limitations that should be considered in interpreting the findings from this study. First, the sample may be described as a nonrandom sample because respondents were only randomly approached at hospital places, including a center for smoking cessation, rather than being randomly selected from a sampling frame. Therefore, the sample may be somewhat biased towards more sensitive categories with respiratory problems. Another important limitation is total reliance on self-report to assign subjects to the relevant smoking status. Due to social, demographic and environmental desirability potentials associated with smoking behavior, some smokers might have denied or underreported their actual smoking status. Furthermore, the perceptions and attitudes of the individuals in this study may not necessarily be generalizable to all individuals within Lebanon. Therefore, larger population-based studies should be conducted in the future to confirm our findings. Moreover, our cross-sectional study evaluated the noncausal association between warning health labels and smoking status; therefore, we are conducting a longitudinal prospective study to determine the impact of pictorial warnings on smoking intentions and behaviors, which is to be published in the near future.

\section{Conclusion}

The present study is, to our knowledge, the first study conducted in Lebanon that evaluates the perception of adult smokers on the effectiveness of textual versus pictorial warnings on cigarette tobacco packages. In our study, lowdependent smokers and highly motivated to quit smokers appeared to be more hypothetically susceptible to shocking pictorial warnings. Motivation to quit was associated with sensitivity to warnings, but not with the presence of all chronic respiratory symptoms. Finally, pictorial warning is a tiny part of the global awareness campaigns for decreasing tobacco smoke. It might be targeting a small part of smokers, whereas another phenotype needs a different message as an incentive to quit smoking.

\section{Acknowledgment}

This work was supported by the Lebanese University educational grants.

\section{Disclosure}

The authors report no conflicts of interest. The authors alone are responsible for the content and writing of this article.

\section{References}

1. World Health Organization. WHO Report on The Global Tobacco Epidemic. Raising Taxes on Tobacco. WHO; 2015. Available from: http://apps.who.int/iris/bitstream/10665/178574/1/9789240694606_eng. pdf. Accessed January 13, 2017.

2. World Health Organization. Global Status Report on Non Communicable Diseases. Description of the Global Burden of NCDs, their Risk Factors and Determinants. WHO; 2010. Available from: http://apps.who.int/iris/ bitstream/10665/44579/1/9789240686458_eng.pdf. Accessed January 13, 2017. 
3. Layoun N, Saleh N, Barbour B, et al. Waterpipe effects on pulmonary function and cardiovascular indices: a comparison to cigarette smoking in real life situation. Inhal Toxicol. 2014;26(10):620-627.

4. Paoletti L, Jardin B, Carpenter M, Cummings KM, Silvestri GA. Current status of tobacco policy and control. J Thorac Imaging. 2012; 27(4):213-219.

5. Ramdas D, Balasubramanian A. Health awareness and youth: a study on the impact of visual and caption in the cigarette packets on youth The International Conference on Communication and Media; October 18-20, 2014 (i-COME'14); Langkawi, Malaysia.

6. Süssenbach P, Niemeier S, Glock S. Effects of and attention to graphic warning labels on cigarette packages. Psychol Health. 2013;28(10): 1192-1206.

7. Wakefield M, Morley C, Horan JK, Cummings KM. The cigarette pack as image: new evidence from tobacco industry documents. Tob Control. 2002;11(Suppl 1):173-180.

8. Pollay RW. The role of packaging seen through industry documents. 2001. Expert Report prepared for: JTI-Macdonald. Imperial Tobacco Canada Ltd and Rothmans, Benson \& Hedges Inc. v. Attorney General of Canada and Canadian Cancer Society (intervenor). Supreme Court, Province of Quebec, District of Montreal. Defense Exhibit D-116. 2001

9. World Health Organization. WHO Framework Convention on Tobacco Control. Geneva, Switzerland: World Health Organization; 2003.

10. Fathelrahman AI, Omar M, Awang R, et al. Smokers' responses toward cigarette pack warning labels in predicting quit intention, stage of change, and self-efficacy. Nicotine Tob Res. 2009;11(3):248-253.

11. Reid JL, Hammond D, Driezen P. Socio-economic status and smoking in Canada, 1999-2006: has there been any progress on disparities in tobacco use? Can J Public Health. 2010;101(1):73-78.

12. Hammond D, Fong GT, Borland R, Cummings KM, McNeill A, Driezen P. Text and graphic warnings on cigarette packages: findings from the international tobacco control four country study. Am J Prev Med. 2007;32(3):202-209.

13. Hassan LM, Shiu E, Thrasher JF, Fong GT, Hastings G. Exploring the effectiveness of cigarette warning labels: findings from the United States and United Kingdom arms of the International Tobacco Control (ITC) Four country survey. NVSM. 2008;13:263-274

14. Borland R, Wilson N, Fong GT, et al. Impact of graphic and text warnings on cigarette packs: findings from four countries over five years. Tob Control. 2009;18(5):358-364.

15. Thrasher JF, Villalobos V, Szklo A, et al. Assessing the impact of cigarette package health warning labels: a cross-country comparison in Brazil, Uruguay and Mexico. Salud Publica Mex. 2010;52(Suppl 2): S206-S215.

16. Borland R, Yong HH, Wilson N, et al. How reactions to cigarette packet health warnings influence quitting: findings from the ITC Four-Country survey. Addiction. 2009;104(4):669-675.

17. Azagba S, Sharaf MF. The effect of graphic cigarette warning labels on smoking behavior: evidence from the Canadian experience. Nicotine Tob Res. 2013;15(3):708-717.

18. Hammond D. Health warning messages on tobacco products: a review. Tob Control. 2011;20(5):327-337.

19. Houts PS, Doak CC, Doak LG, Loscalzo MJ. The role of pictures in improving health communication: a review of research on attention, comprehension, recall and adherence. Patient Educ Couns. 2006;61(2): 173-190.

20. Severtson DJ, Henriques JB. The effect of graphics on environmental health risk beliefs, emotions, behavioral intentions, and recall. Risk Analysis. 2009;29(11):1549-1565.

21. Huang J, Chaloupka FJ, Fong GT. Cigarette graphic warning labels and smoking prevalence in Canada: a critical examination and reformulation of the FDA regulatory impact analysis. Tob Control. 2014;23(Suppl 1): i7-i12.

22. Thrasher JF, Carpenter MJ, Andrews JO, et al. Cigarette warning label policy alternatives and smoking-related health disparities. Am J Prev Med. 2012;43(6):590-600.
23. Hammond D, Fong GT, McNeill A, Borland R, Cummings KM. Effectiveness of cigarette warning labels in informing smokers about the risks of smoking: findings from the International Tobacco Control (ITC) Four Country Survey. Tob Control. 2006;15(Suppl 3):iii19-iii25.

24. World Health Organization. Tobacco labelling and packaging - World Conference on Tobacco; Feb 2015. Available from: http://www.tobaccolabels.ca/2015/02/. Accessed January 13, 2017.

25. Mannocci A, Colamesta V, Conti V, et al. Demographic characteristics, nicotine dependence, and motivation to quit as possible determinants of smoking behaviors and acceptability of shocking warnings in Italy. Biomed Res Int. 2014;2014:723035.

26. Waked M, Salameh P, Aoun Z. Water-pipe (narguile) smokers in Lebanon: a pilot study. Eastern Mediterr Health J. 2009;15(2): $432-442$.

27. Smith J, Woodcock A. Cough and its importance in COPD. Int J Chron Obstruct Pulmon Dis. 2006;1(3):305-314.

28. Heatherton TF, Kozlowski LT, Frecker RC, Fagerstrom KO. The Fagerstrom test for nicotine dependence: a revision of the Fagerstrom tolerance questionnaire. Br J Addiction. 1991;86(9):1119-1127.

29. la Torre G, Saulle R, Nicolotti N, Waure C, Gualano MR, Boccia S. From nicotine dependence to genetic determinants of smoking. In Torre G La, editor. Smoking Prevention and Cessation. London, UK: Springer; 2013:1-21.

30. Cantrell J, Vallone DM, Thrasher JF, et al. Impact of tobacco-related health warning labels across socioeconomic, race and ethnic groups: results from a randomized web-based experiment. PLoS One. 2013;8(1):e52206.

31. Waked M, Khayat G, Salameh P. COPD prevalence in Lebanon: a cross-sectional descriptive study. Clin Epidemiol. 2011;3:315-323.

32. Sabbane LI, Lowrey TM, Chebat JC. The effectiveness of cigarette warning label threats on nonsmoking adolescents. $J$ Consum Aff. 2009;43(2):332-345.

33. Mutti S, Reid JL, Gupta PC, et al. Perceived effectiveness of text and pictorial health warnings for smokeless tobacco packages in Navi Mumbai, India, and Dhaka, Bangladesh: findings from an experimental study. Tob Control. 2016;25(4):437-443.

34. Hammond D, Thrasher J, Reid JL, Driezen P, Boudreau C, Santillán EA. Perceived effectiveness of pictorial health warnings among Mexican youth and adults: a population-level intervention with potential to reduce tobacco-related inequities. Cancer Causes Control. 2012;23(Suppl 1): $57-67$.

35. Fong GT, Hammond D, Jiang Y, et al; ITC China Project Team. Perceptions of tobacco health warnings in China compared with picture and text-only health warnings from other countries: an experimental study. Tob Control. 2010;19(Suppl 2):i69-i77.

36. Kaleta D, Kozieł A, Miśkiewicz P. Pictorial health warnings on tobacco products packages as a part of tobacco epidemic control. Med Pr. 2009;60(5):399-403. Polish.

37. Sychareun V, Hansana V, Phengsavanh A, Chaleunvong K, Tomson T. Perceptions and acceptability of pictorial health warning labels vs text only - a cross-sectional study in Lao PDR. BMC Public Health. 2015;15(1):1094.

38. Mannocci A, Antici D, Boccia A, La Torre G. Impact of cigarette packages warning labels in relation to tobacco-smoking dependence and motivation to quit. Epidemiol Prev. 2012;36(2):100-107.

39. Brewer NT, Hall MG, Noar SM, et al. Effect of pictorial cigarette pack warnings on changes in smoking behavior: a randomized clinical trial. JAMA Intern Med. 2016;176(7):905-912.

40. Cameron LD, Pepper JK, Brewer NT. Responses of young adults to graphic warning labels for cigarette packages. Tob Control. 2015; 24(e1):e14-e22.

41. O'Hegarty M, Pederson LL, Nelson DE, Mowery P, Gable JM, Wortley P. Reactions of young adult smokers to warning labels on cigarette packages. Am J Prev Med. 2006;30(6):467-473.

42. Vardavas CI, Connolly G, Karamanolis K, Kafatos A. Adolescents perceived effectiveness of the proposed European graphic tobacco warning labels. Eur J Public Health. 2009;19(2):212-217. 
43. Nagelhout GE, Willemsen MC, de Vries H, et al. Educational differences in the impact of pictorial cigarette warning labels on smokers: findings from the International Tobacco Control (ITC) Europe surveys. Tob Control. 2016;25(3):325-332.

44. Environics Research Group. The Health Effects of Tobacco and Health Warning Messages on Cigarette Sackages - Survey of Youth: Wave 12 Surveys. Prepared for Health Canada; 2007.

45. Cavalcante TM. Labelling and Packaging in Brazil. National Cancer Institute, Health Ministry of Brazil. World Health Organization; 2003.

46. Kees J, Burton S, Andrews JC, Kozup J. Test of graphic visuals and cigarette package Warning combinations: implications for the framework convention on tobacco control. J Public Policy Marketing. 2006;25(2):212-223.

47. Sabbane LI, Bellavance F, Chebat JC. Recency versus repetition primiting effects of cigarette brand familiarity. J Appl Soc Psychol. 2009;39: 656-682.

48. Gallopel-Morvan K, Gabriel P, Le Gall-Ely M, Rieunier S, Urien B. The use of visual warnings in social marketing: the case of tobacco. J Bus Res. 2011;64(1):7-11.

49. Thasher JF, Rousu MC, Anaya-Ocampo R, Reynales-Shigematsu LM, Arillo-Santillán E, Hernández-Avila M. Estimating the impact of graphic warning labels on cigarette packs: the auction method. Salud Publica Mex. 2006;48(Suppl 1):S55-S66.

50. Hammond D, Wakefield M, Durkin S, Brennan E. Tobacco packaging and mass media campaigns: research needs for articles 11 and 12 of the WHO framework convention on tobacco control. Nicotine Tob Res. 2013;15(4):817-831.

51. Volchan E, David IA, Tavares G, et al. Implicit motivational impact of pictorial health warning on cigarette packs. PLoS One. 2013;8(8): e72117.

52. Hammond D, Fong GT, McDonald PW, Brown KS, Cameron R. Graphic Canadian cigarette warning labels and adverse outcomes: evidence from Canadian smokers. Am J Public Health. 2004;94(8):1442-1445.

53. Hyland A, Li Q, Bauer JE, Giovino GA, Steger C, Cummings KM. Predictors of cessation in a cohort of current and former smokers followed over 13 years. Nicotine Tob Res. 2004;6(Suppl 3):S363-S369.

54. Nourjah P, Wagener DK, Eberhardt M, Horowitz AM. Knowledge of risk factors and risk behaviors related to coronary heart disease among blue and white collar males. J Public Health Policy. 1994;15(4):443-459.

55. Romer D, Jamieson P. Do adolescents appreciate the risks of smoking? Evidence from a national survey. J Adolesc Health. 2001;29(1): 12-21.

56. Koval JJ, Aubut JA, Pederson LL, O’Hegarty M, Chan SS. The potential effectiveness of warning labels on cigarette packages: the perceptions of young adult Canadians. Can J Public Health. 2005;96(5):353-356.
57. Tharsher JF, Arillo-Santillan E, Villalobos V, et al. Can pictorial warning labels on cigarette packages address smoking-related health disparities? Field experiments in Mexico to assess pictorial warning label content. Cancer Causes Control. 2012;23(Suppl 1):69-80.

58. European Commission. Eurobarometer: Survey on Tobacco (Analytical Report). 2009.

59. Mallikarjun S, Rao A, Rajesh G, Shenoy R, Bh MP. Role of tobacco warning labels in informing smokers about risks of smoking among bus drivers in Mangalore, India. Asian Pac J Cancer Prev. 2014;15(19): 8265-8270.

60. Loeber S, Vollstädt-Klein S, Wilden S, et al. The effect of pictorial warnings on cigarette packages on attentional bias of smokers. Pharmacol Biochem Behav. 2011;98(2):292-298.

61. Devlin E, Anderson S, Hastings G, Macfadyen L. Targeting smokers with tobacco warning labels - opportunities and challenges for Pan European health promotion. Health Promot Int. 2005;20(1):41-49.

62. Mead EL, Cohen JE, Kennedy CE, Gallo J, Latkin CA. The role of theory-driven graphic warning labels in motivation to quit: a qualitative study on perceptions from low-income, urban smokers. BMC Public Health. 2015;15:92.

63. Borland R, Yong HH, Balmford J, et al. Motivational factors predict quit attempts but not maintenance of smoking cessation: findings from the International Tobacco Control Four country project. Nicotine Tob Res. 2010;12(Suppl 1):S4-S11.

64. Lee HS, Catley D, Harris KJ. Improving understanding of the quitting process: psychological predictors of quit attempts versus smoking cessation maintenance among college students. Subst Use Misuse. 2014;49(10):1332-1339.

65. Witte K, Allen M. A meta-analysis of fear appeals: implications for effective public health campaigns. Health Educ Behav. 2000;27(5): 591-615.

66. Osler M, Prescott E, Godtfredsen N, Hein HO, Schnohr P. Gender and determinants of smoking cessation: a longitudinal study. Prev Med. 1999;29(1):57-62.

67. Hymowitz N, Cummings KM, Hyland A, Lynn WR, Pechacek TF, Hartwell TD. Predictors of smoking cessation in a cohort of adult smokers followed for five years. Tob Control. 1997;6(Suppl 2):S57-S62.

68. McAllister JM, Lindsay GB, Merrill RM, Perego UA. Cigarette smoking and stages of change among men and women in Kiev, Ukraine. Eur J Public Health. 2002;12(4):302-307.

69. Stead LF, Lancaster T. Interventions to reduce harm from continued tobacco use. Cochrane Database Syst Rev. 2007;(3):CD005231.
Patient Preference and Adherence

\section{Publish your work in this journal}

Patient Preference and Adherence is an international, peer-reviewed, open access journal that focuses on the growing importance of patient preference and adherence throughout the therapeutic continuum. Patient satisfaction, acceptability, quality of life, compliance, persistence and their role in developing new therapeutic modalities and compounds to optimize
Dovepress

clinical outcomes for existing disease states are major areas of interest for the journal. This journal has been accepted for indexing on PubMed Central. The manuscript management system is completely online and includes a very quick and fair peer-review system, which is all easy to use. Visit http://www. dovepress.com/testimonials.php to read real quotes from published authors. 